\title{
Efficiency of Direct Microscopy of Stool Samples Using an Antigen-Specific Adhesin Test for Entamoeba Histolytica
}

\author{
Arzu İrvem¹, Kamil Özdil², Zuhal Çalışkan², Muhterem Yücel ${ }^{1}$ \\ ${ }^{1}$ Department of Microbiology and Clinical Microbiology, Ümraniye Training and Research Hospital, İstanbul, Turkey \\ ${ }^{2}$ Clinic of Gastroenterology, Ümraniye Training and Research Hospital, İstanbul, Turkey
}

Background: E. histolytica is among the common causes of acute gastroenteritis. The pathogenic species E. histolyti$c a$ and the nonpathogenic species $E$. dispar cannot be morphologically differentiated, although correct identification of these protozoans is important for treatment and public health. In many laboratories, the screening of leukocytes, erythrocytes, amoebic cysts, trophozoites and parasite eggs is performed using Native-Lugol's iodine for pre-diagnosis. Aims: In this study, we aimed to investigate the frequency of E. histolytica in stool samples collected from 788 patients residing in the Anatolian region of İstanbul who presented with gastrointestinal complaints. We used the information obtained to evaluate the effectiveness of microscopic examinations when used in combination with the $E$. histolytica adhesin antigen test.

Study Design: Retrospective cross-sectional study

Methods: Preparations of stool samples stained with Native-Lugol's iodine were evaluated using the E. histolytica adhesin test and examined using standard light microscopy at $\times 40$ magnification. Pearson's Chi-square and Fisher's exact tests were used for statistical analysis. Logistic regression analysis was used for multivariate analysis.

Results: Of 788 samples, 38 (4.8\%) were positive for E. histolytica adhesin antigens. When evaluated together with the presences of erythrocytes, leukocytes, cysts, and trophozoites, respectively, using logistic regression analysis, leukocyte positivity was significantly higher. The odds ratio of leukocyte positivity increased adhesin testpositivity by 2,530 -fold $(95 \% \mathrm{CI}=1.01-6.330)$. Adhesin test-positivity was significant ( $\mathrm{p}=0.047$ ).

Conclusion: In line with these findings, the consistency between the presence of cysts and erythrocytes and adhesin test-positivity was found to be highly significant, but that of higher levels of leukocytes was found to be discordant. It was concluded that leukocytes and trophozoites were easily misjudged using direct microscopy. Although microscopic examination of samples stained with Native-Lugol's iodine is a cheap and simple method, the confusion of trophozoites with leukocytes may direct the clinician toward an incorrect pre-diagnosis. Because trichrome staining is difficult and time consuming, and results may vary depending on the technician, this method is not preferred in most laboratories. Therefore, an enzyme-linked immunosorbent assay method, which is a more advanced method than polymerase chain reaction, should be used to distinguish between $E$. histolytica and $E$. dispar in order to achieve an accurate diagnosis. Keywords: Adhesin test, Microscopic examination, Entamoeba histolytica

This study has been presented at the $2^{\text {nd }}$ National Clinical Microbiology Congress, 10-13 November 2013 Antalya Turkey.

Address for Correspondence: Dr. Arzu İrvem, Department of Microbiology and Clinical Microbiology, Ümraniye Training and Research Hospital, İstanbul, Turkey Phone: +90 5323025705 e-mail: arzuirvem93@gmail.com

Received: 10 July $2015 \quad$ Accepted: 1 June 2016 •DOI: 10.5152/balkanmedj.2016.150978

Available at www.balkanmedicaljournal.org

İrvem A, Özdil K, Çalışkan Z, Yücel M. Efficiency of direct microscopy of stool samples using an antigen-specific adhesin test for Entamoeba histolytica. Balkan Med J 2016;33:543-6 
Entamoeba histolytica, which is the causative agent of amoebic dysentery and an important health problem for developing countries, is an important parasite responsible for deaths worldwide. The genus Entamoeba contains following species: Entamoeba histolytica, Entamoeba dispar, Entamoeba moshkowskii, Entamoeba polecki, Entamoeba coli and Entamoeba hartmannii. While pathogenic species E. histolytica causes abscess in various internal organs most notably liver with tissue invasion, Entamoeba dispar which is considered to be nonpathogenic species remains confined to the intestinal lumen without tissue invasion. It is estimated that 500 million people are infected with $E$. histolytica around the world annually; approximately 50 million result in colitis and liver abscess and approximately 100,000 of them in death due to complications resulting from invasive amoebiasis (1). It is observed that infection rate increases in societies with lower socioeconomic status and in crowded living areas due to personal hygiene. Recently, World Health Organization (WHO) recommends to make a specific diagnosis of E. histolytica in the developing countries by using improved diagnostic methods specific for E. histolytica and technologies developed for these countries (2). Currently, specific methods to detecting $E$. histolytica specific adhesin antigen in the stool sample show higher specificity and sensitivity in differential diagnosis (3-5). Rapid and definitive diagnosis of amoebiasis is important for administering treatment in the early stage. In our study, it was aimed to perform microscopic examinations of stool samples sent from various departments to Microbiology Laboratory of our hospital regarding 788 patients presenting due to gastrointestinal complaints and to evaluate the results of ELISA adhesin antigen test specific for E. histolytica together.

\section{MATERIALS AND METHODS}

Stool samples were sent from various departments to the Microbiology Laboratory of our hospital for 788 patients with clinical suspicion of amoebiasis during the period from January 2012 to October 2013. The samples were investigated retrospectively (Ethics Committee Decision No: 18/12 Project No: KOU KAEK 2015/207). At microscopic examinations of stool, approximately $2 \mathrm{~g}$ of stool sample was stained with saline solution and Lugol's Iodine Stain. Preparations that were prepared have been investigated with $\mathrm{x} 10$ and $\times 40$ lenses. Then, E. histolytica adhesin ELISA test (a second generation monoclonal antibody-based ELISA, TECHLAB Blacksburg; VA, USA) was studied from these samples in the direction of the recommendations of the manufacturer. Pearson Chi-Square and Fisher's Exact tests were used for statistical analysis and enter logistic regression analysis was used for multivariate analysis. The results were evaluated in $95 \%$ confidence interval and at a significance level of $\mathrm{p}<0.05$ (Number Cruncher Statistical System; Utah, USA).

\section{RESULTS}

Thirty-eight (4.8\%) of 788 stool samples studied were determined to be adhesin antigen test positive. Sixteen of the samples determined to be adhesin antigen test positive belonged to the female patients; 22 of them belonged to male patients. The difference between female and male patients was not found to be statistically significant $(\mathrm{p}>0.05)$. Mean age was $30.1 \pm 3.2$ years (range:1-75 years). No leukocytes, erythrocytes, cysts or trophozoites were observed microscopically in $23(60.5 \%)$ of 38 stool samples determined to be adhesin antigen test positive. Erythrocyte, leukocyte, cyst and trophozoite test results were determined to be positive in 11 (28.9\%), $10(26.3 \%), 3$ and 2 stool samples, respectively (Table 1). Adhesin test-positivity was found to be significant with Pearson Chi-Square test in the samples determined to be erythrocyte positive ( $p=0.003$ ). Adhesin test positivity was determined to be significant with Fisher's Exact test in the samples determined to be amoeba cyst positive ( $\mathrm{p}=0.015$ ). While erythrocyte, leukocyte and amoeba cyst positivity were statistically significant in logistic regression analysis of microscopic evaluation of erythrocyte, amoeba cyst and trophozoite; trophozoite positivity was found to be non-significant (Table 2). It was

\begin{tabular}{lccc}
\multicolumn{1}{c}{ TABLE 1. Microscopic evaluation and Adhesin test positivity } \\
\hline Microscopic Evaluation & Total & $\begin{array}{c}\text { Adhesin test } \\
\text { negative }\end{array}$ & $\begin{array}{c}\text { Adhesin test } \\
\text { positivity }\end{array}$ \\
\hline Nothing Visible (Leukocyte, & 685 & 662 & 23 \\
Erythrocyte, Cyst, Trophozoite) & 22 & 19 & 3 \\
Leukocyte & 27 & 24 & 3 \\
Erythrocyte & 1 & 1 & 0 \\
Cyst & 3 & 3 & 0 \\
Trophozoite & 34 & 31 & 3 \\
Leukocyte + Erythrocyte & 4 & 3 & 1 \\
Erythrocyte + Cyst & 2 & 1 & 1 \\
Erythrocyte + Trophozoite & 2 & 2 & 0 \\
Leukocyte + Cyst & 3 & 2 & 1 \\
Leukocyte + Trophozoite & 4 & 1 & 3 \\
Leukocyte + Erythrocyte + Cyst & 1 & 1 & 0 \\
Leukocyte + Trophozoite + Erythrocyte & 788 & 750 & 38 \\
Total & & & 3 \\
\hline
\end{tabular}


TABLE 2. Logistic regression analysis (enter method) of microscopic evaluation of erythrocyte, leukocyte and amebic cyst and trophozoite

\begin{tabular}{|c|c|c|c|c|c|c|c|c|}
\hline & \multicolumn{4}{|c|}{ Univariate analysis } & \multicolumn{4}{|c|}{ Multivariate analysis } \\
\hline & \multirow[b]{2}{*}{$\mathrm{p}$} & \multirow[b]{2}{*}{ ODDS } & \multicolumn{2}{|c|}{$95 \% \mathrm{CI}$} & \multirow[b]{2}{*}{$\mathrm{p}$} & \multirow[b]{2}{*}{ ODDS } & \multicolumn{2}{|c|}{$95 \% \mathrm{CI}$} \\
\hline & & & Lower & Upper & & & Lower & Upper \\
\hline Erythrocyte & 0.001 & 4.602 & 2.177 & 9.726 & $0.003 * *$ & 3.465 & 1.518 & 7.912 \\
\hline Cyst & 0.001 & 12.487 & 3.487 & 44.718 & $0.015^{*}$ & 5.704 & 1.402 & 23.201 \\
\hline Trophozoite & 0.066 & 5.897 & 1.183 & 29.403 & 0.067 & 4.786 & 0.897 & 25.522 \\
\hline Leukocyte & 0.001 & 4.426 & 2.046 & 9.575 & 0.150 & 2.050 & 0.772 & 5.447 \\
\hline
\end{tabular}

ODDS ratio: relative risk; CI: confidence interval; P: $p$ value

observed that leukocyte positivity was significantly higher and it masked erythrocyte positivity. With determination of significantly higher rate of leukocyte in adhesin positive samples, it was concluded that trophozoite and leukocytes could not be differentiated very well.

\section{DISCUSSION}

Eighty-five to ninety percent of E. histolytica infections are asymptomatic. No clinical manifestation is observed. The World Health Organization reported that cases determined to have E. histolytica should be treated, whether or not there are clinical symptoms (2). Prevalence is $1-21 \%$ in asymptomatic cases in developing countries. While it is prevalent in all of temperate and tropical regions, it is essentially prevalent in Africa, middle South America and India. Prevalence is reported to be $4 \%$ in high risk groups in developed countries (6). In a study performed in the population of North Eastern Indian population, the prevalence rates of $E$. histolytica, $E$. dispar and E. moshkowskii in 1260 fecal specimens between 2011 and 2014 with molecular methods were determined to be $13.7 \%, 11.8 \%$ and 7.8 ; respectively (7). In a study performed with 500 subjects in Malaysia, the rates of E. dispar, E. histolytica and E. moshkowskii in 93 stool samples considered to be amoebiasis microscopically were determined to be as followings with molecular studies: $13.4 \%, 3.2 \%$ and $1 \%$; respectively (8). In a study performed in Bangladesh, the prevalence of $E$. histolytica in the children living in rural areas was determined to be $8 \%$ with ELISA method (9). In a study performed in Egypt, the prevalence of E. histolytica in 600 children with gastroenteritis was reported to be $20 \%$ with antigen ELISA method (10) and again in a study performed in Pakistan, the prevalence of E. histolytica was reported to be $21.69 \%$ (11). Since the discrimination of $E$. histolytica from the other nonpathogenic species of the genus Entamoeba has not been made in the backdated publications in Turkey, it is difficult to make interpretation regarding its prevalence. However, the prevalence in Turkey is estimated to be $0.4-18.4 \%(5,12)$. E. histolytica is endemic in south and southwest regions of our country. In our study, the prevalence of E. histolytica in the cases with clinical suspicion of amoebiasis was determined to be $4.8 \%$. Consistent with the other studies, no statistically significant difference was found regarding gender in positive cases $(6,12,13)$. Since it is cheap and easy to administer, direct wet mount examination method is the most commonly used method in the diagnosis of amoebiasis. Since it necessitates experienced healthcare professional, the sensitivity of NativeLugol method changes between $10 \%$ and $60 \%$, amebic cyst may be confused with macrophages in stool sample or amebic species such as E. dispar and E. moshkovskii that cannot be differentiated but considered to be nonpathogenic may be present in stool sample; false-positive results can be obtained. Additionally, because the nucleus structure of Entamoeba species cannot be discriminated with precision in some preparations using the direct wet mount examination method, advanced methods such as Trichrome staining or E. histolytica antigen detection can be used. The most reliable discriminative methods for E. histolytica and E. dispar are reported to be demonstration of specific antigens with different methods and determination of specific DNA regions. In evaluation performed with advanced methods, it has been reported that causative agent was $E$. dispar in $90 \%$ of the people determined to be amoebiasis and E. histolytica in $10 \%$ of them $(14,5)$. While E. histolytica positivity has been determined to be at a rate of $43.2 \%, 54.5 \%$ and $72.4 \%$ with antigen-specific ELISA in the samples determined to have amoeba in different studies performed, the rate of ELISA positivity is not known in the samples that are microscopically negative $(5,15,16)$. Since both microscopic method and adhesin ELISA methods were studied in 788 samples in our study, it was determined that 23 (3.3\%) of 685 samples that were microscopically negative were ELISA adhesin test-positive (Table 1). This is an important rate and therefore trichrome staining should be performed together with adhesin antigen specific ELISA method or PCR method in all of samples with clinical suspicion of amoebiasis.

Although direct wet mount microscopic examination of the stool is inexpensive and easy, while the identification of leu- 
kocytes in the stool may distract the clinician from the correct diagnosis due to an inability to discriminate trophozoites and leukocytes, the confusion of Entamoeba histolytica with $E$. dispar and E. moshkowskii, which do not require treatment, directs the clinician toward an incorrect pre-diagnosis. Therefore, methods should be used in combination for the diagnosis of E. histolytica, and in case of need ELISA method which can make discrimination between E. histolytica and E. dispar or more advanced method of PCR should be applicable routinely. In this way, it will be possible to report higher reliability results.

Ethics Committee Approval: Ethics committee approval was received for this study from the ethics committee of Kocaeli University School of Medicine (Date of approval:18 December 2015 Project No: KOU KAEK 2015/207.

\section{Informed Consent: N/A.}

Peer-review: Externally peer-reviewed.

Author contributions: Concept - A.İ.,K.Ö.; Design - A.İ.; Supervision - A.İ., M.Y.; Resource - A.İ., Z.Ç., M.Y.; Materials - A.İ., M.Y.; Data Collection and/or Processing - A.İ., Z.Ç., M.Y.; Analysis and/or Interpretation -A.I., K.Ö.; Literature Search - A.İ., Z.Ç., M.Y.; Writing - A.İ; Critical Reviews - K.Ö.

Conflict of Interest: No conflict of interest was declared by the authors.

Financial Disclosure: The authors declared that this study has received no financial support.

\section{REFERENCES}

1. Ximenez C, Moran P, Rojas L, Valadez A, Gomez A. Reassessment of the epidemiology of amebiasis: State of the art. Infect Genet Evol 2009;9:1023-32. [CrossRef]

2. WHO. Amoebiasis. Wkly Epidemiol Rec 1997;72:97-100

3. el-hamshary EM, el-Shewy KA, Hegazy MM, Zakaria H. Diagnostic potentials of copro antijen detection based ELISA, compored to microscopy in intestinal amobiasis. J Egypt Soc Parasitol 2004;34:601-10.
4. Fotedar R, Stark D, Beebe N, Marriott D, Ellis J, Harkness J. Laboratory diagnostic techniques for Entamoeba species. Clin Microbiol Rev 2007;20:511-32. [CrossRef]

5. Tuncay S, İnceboz T, Over L, Yalçın G, Usluca S, Şahin S et al. The evaluation of the techniques used for of Entamoeba histolytica in stool specimens Turkiye Parazitol Derg 2007;31:188-93.

6. Yüksel P, Çelik DG, Güngördü Z, Ziver T, İzmirli S, Yakar H et al. Entamoeba histolytica Lectin Antigen from stool specimens by ELISA method: 3 Year Data. Klimik Dergisi 2011;24:150-3.

7. Nath J, Ghosh SK, Singha B, Paul J. Molecular epidemiology of Amoebiasis: A cross-sectional study among North East Indian population. PLoS Negl Trop Dis 2015 Dec 3;9:e0004225. [CrossRef]

8. Anuar TS, Al-Mekhlafi HM, Abdul Ghani MK, Abu Bakar E, Azreen SN, Salleh FM et al. Molecular epidemiology of amoebiasis in Malaysia: Highlighting the different risk factors of Entamoeba histolytica and Entamoeba dispar infections among Orang Asli communities. Int J Parasitol 2012;42:1165-75. [CrossRef]

9. Haque R, Faruque AS, Hahn P, Lyerly D, Petri WA Jr. Entamoeba histolytica and Entamoeba dispar infection in children in Bangladesh. J Infect Dis 1997;175:734-6. [CrossRef]

10. Hegazi MA, Patel TA, El-Deek BS. Prevalance and characters of Entamoeba histolytica infection in Saudi infants and children admitted with diarrhea at 2 main hospitals at South Jeddah:a re-emerging serious infection with unusual presentation. Braz J Infect Dis 2013;17:32-40. [CrossRef]

11. Tasawar Z, Kausar S, Lashari MH. Prevalance of Entamoeba histolytica in Humans. Pak J Pharm Sci 2010;23:344-8.

12. Yildırım D, Hasbek M, Nur N. Analysis of intestinal ameobiasis in patients with dairrhea by adhesin antigen test and direct microscopy. Turkiye Parazitol Derg 2014;38:155-8. [CrossRef]

13. Alver O, Topaç T, Töre O. Evaluation of two methods (Nativelugol preparation and enzyme -linked immunosorbent assay) for detection of Entamoeba histolytica in stool Ssamples. Turkiye Parazitol Derg 2015;39:185-9. [CrossRef]

14. Braga LL, Mendonca Y, Paiva CA, Sales A, Cavalcante AL, Mann BJ. Seropositivity for and intestinal colonization with Entamoeba histolytica and Entamoeba dispar in individuals in northeasten Brazil. J Clin Microbiol 1998;36:3044-5.

15. Taylan Özkan 2005. Rutin Dışkı Bakısına Alternatif: Antijen Tarama Yöntemleri.14.Ulusal Parazitoloji Kongresi.

16. Delialioglu N, Aslan G, Ozturk C, Ozturhan H, Sen S, Emekdas G. Detection of Entamoeba histolytica antigen in stool samples in Mersin, Turkey. J Parasitol 2008;94:530-2. [CrossRef] 